\title{
Contradictions and Ambiguities: School Management Teams' Views on School-Based Violence in Urban South Africa

\author{
Dr Tshilidzi Netshitangani
}

\author{
Department of Educational Leadership and Management, University of South Africa \\ Email: Netsht1@unisa.ac.za
}

\section{Doi:10.5901/mjss.2014.v5n27p782}

\begin{abstract}
This article discusses the findings of a study conducted in Gauteng, South Africa. This qualitative study examined principals' and educators' notions in understanding school-based violence and school safety. Individual and focus group interviews were utilised to collect data from the school management teams (SMTs) that included school governing bodies (parent component). Among the major findings of the study, was that principals and educators have a diverse understanding and perception of the concept of violence, school-based violence as well as safety. The findings also suggest that there are divergent views on bullying; some educators maintain it is a normal occurrence while others believe that it is a problem that needs to be resolved. School safety is not always perceived as urgent even though there might be frequent violent acts happening at the schools. The article recommends the development of school policies that address the different forms of school violence. In addition, there must be intensive training for school-based professionals in order for them to have effective strategies to combat violence in schools. Violence affects teaching and learning; it is then crucial to underscore effective strategies that need to be pursued right from initial teacher education.
\end{abstract}

Keywords: educators, safety, violence reduction strategies, school violence, bullying

\section{Introduction}

In 2012 the South African minister of Basic Education declared the following statement, "We have been experiencing a number of challenges in relation to safety in schools. ... We reiterate that there is no place in our schools for violence, drug-abuse, sexual harassment and other criminal acts because they pose a very serious barrier to learning and to the inculcation of values and ethics of a just and caring society" (Statement on safety in schools from the South African Minister of Basic Education, Mrs Angie Motshekga, 12 November 2010). These words illustrate that safety at schools remains a gnawing concern despite the implementation of a wide range of safety measures by different stakeholders in South African schools. These safety measures include... However, it is interesting to note that, school based violence is a major concern not only in South Africa but globally (Diamond 1999; Barak, 2000; Reza, Mercy, and Krug 2000; Daniel, Southall, and Lutchman, 2005; Mayer, 2008).

In South Africa, apartheid has left behind vestiges of a 'culture of violence'. This was a past filled with political and state-sponsored violence has resulted in a contemporary, democratic South African society that is characterised by high and unacceptable levels of violent crimes. The culture of violence was pervasive in South Africa right from many decades ago when there were protests to change the curriculum and many of the parents were involved in the resistance struggle. South Africans were affected by the violence and even in the post-apartheid era, they are still affected by the violence (Mncube and Harber, 2013). Thus violent protests are more likely to be acceptable to them (Mattews, et al, 1999). The culture of violence might be perceived as "normal" by the children because even though government has anti-violence policies entailed in the Constitution, much of the rhetoric of political leaders is pro-violence. Loots, (2005) asserts that, because crime and politics have been closely linked in South Africa's past, the use of violence for political and personal aims has become endemic in South African society.

In the context of South Africa, principals have had to implement a wide range of measures that have been developed by the Department of Basic Education (DoBE); and by School Governing Bodies (SGBs) in order to eliminate school-based violence from the rubric of the country's nascent post-apartheid schooling system. Such measures include Safer Schools Programmes; Collaboration with the Centre for Justice and Crime Prevention; Safe Schools Call Centres; and Local initiatives of provincial education departments with schools that are experiencing recurring incidents of violence and crime, need to translate into direct results in order for principals to manage schools effectively. Initiatives at school level comprise School Safety Committees (SSC); Adopt-a-Cop; School Governing Body/Parental involvement; 
Bambanani volunteers and use of South African Police Service (SAPS) reservists.

Despite that the country's Safer Schools Campaign has made major gains, much more still needs to be done if schools are to focus on reducing violence. Reducing school violence is important because of three main reasons identified by Burton and Leoschut (2012): firsly, violence at school may result in decreased educational performance and increased isolation, and may place both their mental and physical health at risk. Secondly, violence-free schools have a potential to contributeto social cohesion. And lastly, eliminating school violence can make a substantial contribution to the development capacity of countries. It is therefore important to determine when the educators consider violence as a serious problem. To this effect, Astor et al. (1997) argue that all responsible stakeholders will not succeed in initiating and implementing the violence reduction interventions if they do not perceive a problem.

\section{Literature Review}

\subsection{Conceptualising school violence}

School violence can generally be described as threats, weapon possession, or physical conduct or intimidation perpetrated against learners (choose one) and staff while at school or traveling to and from school (Lintott, 2004). Van den Aardweg and Van den Aardweg (1988), cited in Zulu et al. (2004:70), define school violence as any behaviour of learners, educators, administrators or non-school persons, attempting to inflict injury on another person or to damage school property.

Internationally, violence affects schools and may be perpetuated by schools (e.g. Harber 2004; Pinheiro 2006; PLAN 2008; Smith \& Vaux 2003). For example, bullying, which is one form of violence may be learned outside the school but perpetuated inside the school because the school ignores it or doesn't deal with it satisfactorily. As Burton and Leoschut (2012: 53) put it "Schools are microcosms of the communities in which they are located; thus the violent acts occurring in schools are influenced by many family and community-level risk factors that serve to heighten susceptibility to victimisation". Violence may also involve different actors at different times inside the school, for example, learners may bully each other, teachers may bully learners, learners may bully teachers, parents may bully teachers, and principals may bully teachers or be bullied by them. Addressing school based-violence is the responsibility of all concerned stakeholders. Thus, educators, learners, school management teams (SMTs), and parents need to be committed to implementing the violence reduction strategies.

Learners are exposed to various kinds of crime and violence at schools, including physical and sexual assaults, robberies, intimidation, bullying, shootings, stabbings, gangsterism and drug trafficking. It may also involve different actors at different times inside the school, for example, learners may bully each other, teachers may bully learners, learners may bully teachers, parents may bully teachers and principals may bully teachers or be bullied by them.

School violence is of particular significance in South Africa. The findings reported by Burton and Leoschut (2012: 11) show that on the whole, one in five learners (22.2\%) had succumbed to some form of violence while at school in the 12 months between August 2011 and August 2012. Recent incidents of school violence reported in South African Council of Educators (SACE) report (SACE, 2011) include:

- the case of the random killing of 16 year old Jacques Pretorius by Morne Harmse with a samurai sword at a Technical High School on the West Rand in Gauteng.

- the stabbing to death of a grade nine learner with a pair of scissors;

- the axe killing of an eight-year old boy by two school peers;

- the stabbing to death of Mfundo Ntshangase, a grade 11 student, at a house party;

- and the repeated violence in the form of shootings, drug deals, assaults and rapes on the grounds of schools on the Cape Flats

The following recent incident of violence was also reported: "A pupil from Glenvista High School in south Johannesburg has been suspended for allegedly assaulting a teacher and now faces a disciplinary hearing" (Mail \& Guardian, 2013).

Bullying is a major form of violence in schools. It is critical to mention bullying because research shows that certain forms of violence, specifically bullying, were found to create vulnerability for other more serious and criminal victimisations (Burton and Leoschut, 2012: 11). Ttofi and Farrington (2011; 28) indicate that the definition of school bullying includes physical, verbal, or psychological attack or intimidation that is intended to cause fear, distress, or harm to the victim; an imbalance of power (psychological or physical) with a more powerful child (or children) oppressing less powerful ones; and repeated incidents between the same children over a prolonged period of time. 
However the report by the World Health Organization's (WHO) (WHO 2002:29-30) points out that reducing or eliminating bullying is more difficult because many teachers and parents view bullying as an inevitable part school life and growing up, though this isn't necessarily the case. The report also details the consequences of bullying, loss of selfesteem, shame, anxiety, truancy, concentration problems, reactive aggression, stress and serious psychological problems and even suicide. The bullies themselves also suffer from anxiety and depression and are at a higher risk of suicide and self-harm as well getting involved in criminal activity (PLAN, 2008:36-41).

Schools are supposed to be safe environments free from violence in any form. Prinsloo (2005:5) defines a safe school a school that is free of danger and where there is an absence of possible harm, a place where non-educators, educators and learners may work, teach and learn without fear of ridicule, intimidation, harassment, humiliation, or violence. A report by the South African Institute of Race Relations (SAIRR) (2008) suggested that only 23\% of South African learners said they felt safe at school. Moreover, according to the findings of the study by Burton and Leoschut, 2012: 33) fear was found to be common at secondary schools in South Africa. Teachers are supposed to be instrumental in the elimination violence so that schools can be safe. This can be achieved if teachers are able to recognise violence incidents, and if they endeavour to find common grounds of eliminating school violence despite their diverse views and understanding. It would also be easier for teachers to succeed in violence reduction if they understand what school violence is and if they accommodate each other's different views of both the concepts of violence and safety.

\subsection{Educators and school violence}

"Teachers have a critical role in efforts to reduce these types of risk behavior" (Marsh, McGee, \& Williams, 2009: 246). Regarding this, the studies by Marsh, McGee, Nada-Raja, \& Williams $(2008 ; 2009)$ showed that there was a lack of common understanding of learners' risk behavior which may impact negatively on efforts to reduce its prevalence. Research shows that educators cited several reasons for non-intervention to violence in schools including that bullying was viewed as a typical childhood behavior with no serious consequences (Mishna, Scarcello, Pepler, \& Wiener, 2005: 719). In addition, an interesting finding by Mishna, Scarcello, Pepler, \& Wiener (2005) was that the nature of the school environment influenced the teachers' ability to identify and address bullying. In this regard, teachers in a more charged environment with much rougher kids find it difficult to recognise violence. On the other hand, teachers in less violent schools were said to be less vigilant because they didn't want to lose their good reputation. These perceptions do not mean that there is no violence in those schools.

Research globally suggests teachers and students have perceptions about violence and its extent (Astor, Behere, Fravil, \& Wallace, 1997; Marsh et al, 2009; Mishan et al, 2005). Therefore teacher differences must be considered to understand and address school violence.

According to a study by Kallestad and Olweus (2003), the factors that foretell the degree to which teachers implemented the Olweus Bullying Prevention Program included their views on the importance of staff in addressing bullying, the amount of program information they read, their perceptions of the degree of bullying in their classroom, their own experiences of victimization as a child, and their emotional responsiveness and empathy towards children who are bullied.

Siann, Callaghan, Lockhart, and Rawson (1993) conducted the study to check teachers' views on bullying, which revealed that ambiguity and teachers' own subjective responses to incidents are inherent in bullying.

Teachers have to respond to incidents of violence and they must be able to recognise and respond to bullying and any violent incident as well as implement programs. For this reason, Boulton (1997) conducted a study which focussed on teachers' understanding of bullying and the factors that might influence how they recognize and respond to bullying incidents. Teachers' understanding may well determine whether they see an incident as bullying and whether they intervene appropriately. The study Boulton (1997) showed that most of the teachers considered physical assaults and threats bullying; however, a significant proportion did not view behaviours such as exclusion or name calling bullying. Moreover, according to the findings by Townsend-Wiggins, (2001), teachers' understanding of bullying, particularly relational bullying was limited.

In their study, Craig, Henderson, and Murphy (2000) examined the effects of contextual and characteristics of prospective teachers on their attitudes towards bullying and on their interventions. The study revealed that attitudes and empathy played a role in shaping their definition and view of bullying, their perceptions of the seriousness of bullying, and their probability of intervention.

Therefore, according to Laufer and Harel (2003) it is crucial to determine the understanding and perceptions of educators of school-based violence. Moreover, according to Astor et al. (1997: 55) "Awareness of violence as a problem is important in developing school-based interventions to reduce violence". 
In addition, a study conducted by Mncube and Harber (2013) which investigated the dynamics of violence in schools in South Africa, showed that learners were reluctant to report incidents of violence because educators did not do anything about it. Such kind of behavior and perception of school-based violence by educators may have a negative impact on the success of violence reduction in schools.

The concerns raised above and the literature review give rise to a critical concern of whether it is only the violence reduction strategies that are not effective or if the diverse understanding and perception of what school-based violence shape and direct the manner in which these strategies are implemented. The issue here is that if teachers do not think violence in schools is as a worrying issue, they will not be motivated to implement violence reduction strategies with the seriousness it deserves. On the contrary, if violence is understood to be a debilitating factor to teaching and learning by principals and teachers, they will endeavor to eliminate it. Thus the focus of this article is on the understanding of the educator's school-based violence in schools. This will be done by analyzing the accounts of the educators and SMTs of public secondary schools of in Gauteng South Africa. According to Burton and Leoschut, 2012), violence is aggravated by a combination of the different settings in which school children find themselves, as well as the people that they come into contact with in these contexts.

\section{Research Design and Methods}

\subsection{Methodology}

This article is based on a pilot study that examined school management teams' and educators' experiences of violence in schools, its causes, its impact on teaching and learning and how they address it. Qualitative research methodology was used to conduct the study. During the period at which the study was conducted, the media had publicised the violencerelated incidents taking place in schools to a great extent, and that warranted a more comprehensive study in order to understand the causes of violence in South African schools.

\subsection{Sample selection}

Four schools in Gauteng province were visited. Typical case sampling was used to select the sites for the research. Schools that had experienced some form of violence, either serious or light violence-related incidents, were selected by reviewing newspaper articles and by asking the provincial officials to recommend the schools. The choice and rationale for the four schools sampled in the study reflected the nature, rather than the type, of the investigation. (Strydom, 2002: 211). The four schools were each viewed taking into account their unique and individual uniqueness (Fouche, 2002: 276).

\subsection{Data collection}

Interviews were used to gather data. Semi-structured interviews with open-ended questions were employed in order to allow the interviewees to use their own ways of defining their own worlds, and to raise other issues important to them that may not have been included in a schedule prepared by a researcher (Marshall, and Rossman, 2010; Patton, 2008: Silverman, 2010: Flick, 2009). Data was gathered from principals, school management teams (SMTs) and other educators, and the parental components of school governing bodies (SGBs). Data collection for the study therefore involved desk review of relevant documents and materials, reports, evaluations, previous studies, newspapers and related policies as well as in-depth interviews with principals and focus-group discussions with SMTs, educators and SGBs.

Focus group interviews were used because they encourage participation and interaction amongst participants and this creates a dynamic context where participants, together, create meanings concerning the research questions (Krueger, 2009). Each principal was interviewed individually. Variations of three to five SMT members and educators were interviewed in focus groups in each of the four schools. One SGB member (parent component) from each school was also interviewed to triangulate the data.

\subsection{Analysis of data}

Analysis was done thematically using predetermined themes from the literature. Emerging themes from the data were also analysed and interpreted. Similar responses were grouped together into categories. Similar codes were aggregated to form a major idea from the data (Cresswell, 2012). 


\subsection{Ethical consideration}

As a study that involved research on human subjects, the collection of private or personal information, or the participation of individuals in individual interviews and focus group interviews was designed in such a way that it protected the privacy, dignity, and integrity of the respondents. This was accomplished by ensuring confidentiality and anonymity to all participants. In addition, to protect the learners who were involved in violence-related incidents, the real names of the schools were not used when reporting on the findings. Instead, the schools were referred to as school 1, school 2, school 3 , and school 4.

\section{Discussion of Findings}

\subsection{Educators' views of what violence is}

Respondents expressed varied opinions regarding the meaning of the concept, 'violence'. These views were drawn from the responses to different questions during the interviews.

Responding to the question: What is your understanding of school-based violence, some divergent terminological and conceptual points of view were presented, especially on the following critical nuances:

Some respondents were of the view that the term "violence" is broad and needs categorisation, as there are various forms and levels of violence. They cited the following examples:

- bullying is an expression of anti-social behaviour

- swearing

- vulgar and abusive language are viewed as a form of psychological/emotional violence;

- fighting, stabbing with a weapon, are viewed as examples of physical violence, which was generally regarded as the most severe form on school premises by some educators;

- boys touching girls on their bodies (e.g. breasts, backsides) against their (girls') will is viewed as constituting sexual harassment and it was referred to as a form of psychological/emotional violence.

Another view of the understanding of violence by the educators emerged when the educators responded to the question: Have you experienced acts of violence in the school? The participants stated that there is bad behaviour among learners and in their responses it appeared as if bad behaviour was not a serious issue because it is frequently identified in schools. They also said that there was no violence in the schools but rather accidents and as such their schools had no records of violence in the previous years. Surprisingly they mentioned the killing of one of the learners by another learner which is an obvious violent act. The issue here is that the act of fighting is violence and for the educators to refer to the killing as not violent is problematic. These views were supported by the comments made by educators:

Our school has no records of violence for the past thirty years, except the killing case in their opinion is an accident because the students were fighting over a partner and one accidentally killing the other which was not a deliberate action (Principal)

No incident of violence as such here where a learner physically striking a teacher or colleague because he/she is angry, not at all, except that case which was the first one. It was a play, where the learner was blindfolded by colleagues and he fell on the roof injuring him in the process, which is long time ago and was an accident not violence. No punching, nothing, nothing, but for bad behaviour we do have and that is everywhere even in the university. (Educator)

They sometimes push each other and some learners fall and get seriously injured, but the other learner was just pushing with no intention to injure him (Educator)

Further, the respondents contended that not all forms of psycho-socially unacceptable behavior are necessarily "violent". They indicated shoving another learner might not be violent, but a shove resulting in the other learner fatally falling to the ground could invariably reverse the former equation. Again the ambiguity and contradiction here is that, student's pushing is not seen as violence. What is even more surprising is that because pushing each other is not seen as violent, even the serious injury that result from the pushing cannot be seen as deliberate, hence not violence. However, it was generally agreed by the respondents that the intensity, degree, and result of an action became major factors in the determination of whether the acts were seen as "violence" or not.

From the statements uttered by the SMTs it is clear that the issue of what constitute violence was unclear. After a discussion of what constitutes "violence", participants agreed that all behaviour that involves verbal abuse and/or punching aimed at inflicting pain or harm, is regarded as violent behaviour. Aggressive behaviour that is destructive to lessons or disturbs the learning environment is classified as "violence". When asked to specifically describe an incident of 
violence experienced in the school, it was realised that the teachers were reluctant to provide detailed explanation of what happened in those particular incidents. Similar impression was observed when participants were asked to comment on the frequency of violent incidents. They repeatedly stated that there was no violence in the schools even though there were violent incidents that happened in those schools. Contradictory and unrealistic as it may have sounded participants repeatedly indicated that there is no violence in the school which implies that the schools are "violence-free" and as a result the issue of frequency of violence seemed inappropriate and not relevant. While the notion of "violence" was subjected to both a narrower and broader connotation, these participants' utterances show that the schools have, in varying degrees experienced some form or the other of unacceptable conduct by some learners.

\subsection{Educators' understanding of the concept of 'school-based violence'}

Contradictory views emerged when respondents were expressing their views on their understanding of "School-based violence". All the respondents virtually agreed that a school is a place where learners come to learn as such violence that occurs cannot be referred to as 'school-based based'. The respondents pointed out that the unbridled levels of violence occurring in society find expression in the minds of some learners, and are executed at school on other learners and educators and thus it cannot be referred to as 'school-based'. Regarding this, one educator said:

There is no such thing as 'school-based violence (SMT member)

It's not school-based violence, it is violence that children commit because they have learnt it from outside the school yard, and some fight because of issues that started outside the school (SMT member)

What in fact these educators were saying in the statement above was that there is a correlation between both the internal and external schooling environments regarding the prevalence of forms of violence in the school. Looking at this view critically, these respondents appear to espouse some social values which they apply or practice at school. As an agent for moral rectitude, the school rewards appropriate behaviour and sanctions undesirable conduct in accordance with regulatory instruments at its disposal. Interestingly, what these educators are saying is in agreement with public perceptions of school violence being linked to factors external to the school. Laub and Lauritsen (1998, p. 127) state that

"... conventional wisdom holds that school violence is a reflection of violence in the broader social context, that is, violence is imported into a school by the students, and by intruders from the neighbourhoods surrounding the school." Factors outside of school, such as exposure to crime, violence, drugs, as well as family factors (parental involvement in crime, violence, drugs, and whether or not the student has only one parent) also increase the likelihood of violent student behaviour (Kandakai, Price, Tellojohann, \& Wilson, 1999; Kotlowitz, 1991).

From the common understanding by educators, and given what they said about not having the prevalence of violence in the schools, the contradiction and ambiguity becomes clear. This contradictions and ambiguities pose a serious challenge to the elimination of violence in schools. Indeed, the lack of mutual understanding amongst all stakeholders is a deterrent to implementing violent reduction strategies (Marsh et al. 2008)

\subsection{Educator's views on weapons in schools}

Some respondents have expressed their concern on the use of the term 'weapons'. They held the view that the purpose and use to which an object is put, should characterize its categorization or classification as a weapon. This was raised because some of the objects that are considered to be weapons are objects that are useful and essential for teaching and learning. This is how one participant expressed it:

They (learners) do not use weapons like a gun, but there are other instruments like the pair of scissors that are not weapons but are used as a weapon. ...the problem is that there is now a rule that learners are not allowed to bring scissors to schools. (SMT member)

The concern here is that much as forbidding learners to bring to school some objects that can be used to hurt others, it can equally be a prohibitive factor of teaching and learning because instruments like scissors and protractors are used by both educators and learners in the classroom for learning projects. 


\subsection{Educator's views on frequency of violent incidents in schools premises}

Regarding the frequency of incidents of violence it was indicated that violence occurs very rarely, and not often. In response to the question 'have you experienced violent incidents in the school?' the participants' responses indicated that incidents of violence do occur in the school premises but they were not serious ones, and depending on their own interpretation of "violence" participants in all four schools conveyed that incidents of crime and violence in the school were an infrequent occurrence. Further efforts through probes compelled them to say a little more about the incidents in the schools. However, educators seemed defensive and protective with regards to the image of the schools. The unhappiness about the inclusion of the sampled schools in the study was thus expressed by most participants. This observation was portrayed by participant when he commented that:

Even though we had about four incidents in the past six months, our school is still better as compared to other schools in Johannesburg. I don't know why you are involving our school in this study. (SMT member)

The view that admitting to the prevalence of violence in schools could damage the reputation of the schools can also be one of the explanations why the educators did not openly admit to the seriousness of school violence as a problem, hence they saw no need for their schools to be used for data collection. When requested to describe the incident of violence involving stabbing of a boy in one of the schools, participants clearly insisted that they do not want to comment. Refusal to comment was an indirect admission that the incident that occurred is a contradiction to what they expressed as 'violent free schools". One of the interviewees had this to say:

The department is busy with the case, we are not sure we can comment on it, we don't want to say anything about it... (SMT member)

The educators' unwillingness to describe what exactly happened in that particular incident could again be attributed to a fear of legal implications of the case or doubts the ethics of privacy and confidentiality in data gathering assured to them before the beginning of the interviews or both. Nonetheless, these educators' responses presented contradictions and ambiguities.

One of these schools had a very serious violent incident in which a learner stabbed another learner with a scissors but it was very surprising that the educators felt that the school had no serious violent incidents and that the schools are violence free. Probing further to broaden their conception of violence, participants said that they only experienced beating incidents and some minor misbehavior which were attributed to psychological disorders. Such kinds of utterances suggest that those acts cannot be viewed as violent behaviour. One of the participants expressed it in the following response:

The school is a special school for handicapped learners so there are some behavioral deficiencies on the part of learners, which negatively affects their social interaction. (SMT member)

Given that all the schools were selected purposefully for the reason that there were violent incidents that took place, it was very ironical and contradictory that the educators in those schools still felt that violence was not a serious issue in their schools.

More contradictions and ambiguities arose when the researcher probed further to find out what was perceived as serious and not serious violent incidents. In their responses participants specified that serious ones may include killing or injuring while less serious ones may be fighting over a lover and misunderstanding arising when learners are on the playground. In the context of this delineation, participants indicated that in the past few years they experienced an average of four less serious incidents and one serious incident in a month in the school.

While there is relatively a general increase in the occurrence of violence in schools throughout the country (The Human Rights report on violence in schools, 2008), it is surprising then that seemingly these educators think that the violent acts are isolated and sporadic occurrences. A critical question then is that, how do these SMT members then consider it an urgent social malady that calls for urgent elimination if this is their view?

\subsection{Educator's views on of school safety}

Contradictions were also evident in the manner in which the different educators viewed and understood safety in schools. This was expressed in terms of how safe and secure they feel when in schools yards. 
On the one hand some participants said that they felt safe in the school premises despite the existence of various forms and levels of violence in schools. These forms of violence were mentioned by the participants when they were asked to relate particular incidents of violence experienced. While the notion of "violence" was subjected to both a narrower and broader connotation, there was a perception that the schools had, in varying degrees experienced some form or the other of unacceptable conduct by some learners. Some milder forms of violence were inclusive of swearing at teachers and at each other, physical fights, pushing and stealing. In spite of the fact that these participants constantly expressed that violence was not such an issue in their schools they mentioned serious incidents of beating each other; using bricks to fight; stabbings by different object like knives and scissors; gangsterism and killings. Nonetheless, when responding to the question: Do you feel safe in the school grounds? There was generally an agreement that there is safety in the schools. In view of this, participants generally indicated that they were safe. Two male participants responded positively and succinctly said:

We feel very safe here at school, not scared. (SMT member)

Not at all, we are safe. We are on guard. (SMT member)

How then will these SMTs feel the need for the urgency in reducing school violence if they think it is not serious and they feel safe?

On the contrary, the female teachers opposed this view indicating that sometimes they feel unsafe as expressed in the comment below by one female teacher:

\author{
Sometimes we don't feel safe because learners intimidate us in class making us feel uncomfortable at times, particularly \\ the young female teachers. (SMT member) \\ After the incidence of stabbing, I was not feeling safe, I am afraid to even intervene because some time ago a teacher \\ had a punch from a learner. (SMT member)
}

Female teachers appeared to feel more unsafe when compared to their male counterparts. Asked what they do when a learner intimidates them, they indicated that they ignore and pay no attention to such learners but this does not affect teachers' attitude towards other learners. It is obvious from these utterances that an issue of safety is viewed differently by educators which may cause a challenge when these educators are to implement violence reduction strategies.

The ambiguities also play themselves when these participants express that their schools are generally safe environments while at the same time they enumerated a number of violent incidents that suggest that their schools are not as safe as they are saying they are. When asked to relate particular incidents of violence experienced in their schools, participants were reluctant to talk about them and did not provide detailed description of what happen during some of the incidents. Further probes compelled them to mention the following incidents: On the day of the interview, a disciplinary hearing was going to be conducted of a case of an unrepentant boy who had been problematic in every grade that he had gone through in the school (grades 8-11), showing signs of extreme aggression to any authority figure; a boy was beaten by his schoolmate; a boy had stabbed another to death during a fight; one learner was hit with a brick; a learner had killed another learner with a Samurai sword; and learners fighting for a lover.

Such incidents are no doubt indication of the prevalence of serious violent acts that warrant a search for developing and implementing safety measures in schools.

\title{
5. Conclusions and Recommendations
}

The findings of this study suggest that various school roleplayers have different views about the concept of violence. Their views differ firstly on their understanding of the concept of 'school-based violence'; secondly, on the use of the term 'weapons', thirdly, on their perception of the frequency of incidents of violence in school premises; and lastly, on school safety. Given their different views about violence in schools, SMTs need to find common grounds to tackle it.

The issue here is that if teachers do not regard school violence as an issue of concern, they will not be motivated to implement violence reduction strategies. Violence should be addressed directly and educators who understand the need for this will be able to uphold the culture of learning and teaching in their schools. Meticulous school leaders and their dependable teachers will continually try to understand school violence before they trample it in their schools. As evident in the date above, there is a general belief that school violence might not be as serious as it usually purported to be. Some argue though that the best way to reducing violence is to approach it as 'creating school safety' which is more positive rather than approaching it as 'reducing violence' which is negative. As the results of this study demonstrate, 
behaviours such as pushing, grabbing, kicking, punching, fistfights, and property stolen by force were reported by an overwhelming majority of interviewees, it is suggested that these more common violent behaviours be used as a threshold to create a zero-tolerance school environment for violence.

It is therefore recommended that the schools should prioritise the development of school policies that address the different forms of violence. School management teams should see to the implementation of these policies. It is also crucial for educators and school management teams to receive intensive training to understand what violence is, how it affects teaching and learning and how to deal with it. Such training should inform educators that any form of physical assault or potentially lethal violence should be sufficient to determine that a school has a big problem. The perception of a problem should not be contingent solely on the existence of multiple events of severe violence. Of more importance is the introduction of such training at teacher training level. If teachers are equipped with the knowledge of what violence and bullying is and its long term consequences, they will be able to notice it and intervene. These recommendations are in agreement with those that were suggested by the respondents.

\section{References}

Astor, R. A., Behere, W. J., Fravil, K. A., \& Wallace, J. M. (1997). Perceptions of school violence as a problem and reports of violent events: A national survey of school social workers. Social Work, 42:1, 55-68.

Barak, A. (2000). The Internet and suicides: another expression of the two faces of the Internet. Haye utz Hachinuchi, 9, 111-128 (in Hebrew).

Boulton, M. J. (1997). Teachers' views on bullying: Definitions, attitudes and Ability to cope. British Journal of Educational Psychology, $67,223233$.

Burton, P. \& Leoschut, L. (CJCP) (2012). School Violence in South Africa. Results of the 2012 National School Violence Study.

Craig, W. M., Henderson, K., \& Murphy, J. G. (2000). Prospective teachers' attitudes toward bullying and victimization. School Psychology International, 21:1, 521.

Cresswell, J. W. (2012). Qualitative inquiry and research design: Choosing among five approaches. Sage publications.

Daniel, J., Southall, R., \& Lutchman, J. (eds) (2005). State of the Nation: South Africa 2004-2005. Cape Town: HSRC Press.

Diamond, L. (1999). Developing democracy: toward consolidation. Baltimore: JHU Press.

Flick, U. (2009), An introduction to qualitative research. London: Sage.

Fouché, C. B. (2002). Research strategies. Research at grassroots for social sciences and human service professions.

Harber, C. ( 2004), Schooling as violence: How schools harm pupils and societies. New York: Taylor and Francis Group.

Kallestad, J. H., \& Olweus, D. (2003). Predicting teachers' and schools' implementation of the Olweus Bullying Prevention Program: A multilevel study. Prevention and Treatment, 6:2 [Article A] Available at http://content.apa.org/journals/pre/6/1/21. Accessed on 15 January 2006.

Kandakai, T. L., Price, J. H., Telljohann, S. K., \& Wilson, C. A. (1999). Mothers' perceptions of factors influencing violence in schools. Journal of School Health, 69:5, 189-195.Kotlowitz, 1991)

Krueger, R. A. (2009), Focus groups: A practical guide for applied research. London: Sage.

Laub, J.H. \& Lauritsen, J.L. (1998). The interdependence of school violence with neighbourhood and family conditions. In

Violence in American schools: A new perspective. In Elliot, D.S., Hamburg, B.A. \& Williams, K.R. (Eds.). (127-158). Cambridge University Press: New York, NY.

Laufer, A., \& Harel, Y. (2003). The role of family, peers and school perceptions in predicting involvement in youth violence. International Journal of Adolescent Medicine \& Health, 15:3, 235-244.

Lintott, J. (2004). Teaching and learning in the face of school violence. Georgetown Journal on Poverty, Law, and Policy, 11, 553-580.

Mail \& Guardian. 2013. School Violence. 20 September.

Marsh, L., McGee, R., Nada-Raja, S., \& Williams, S. (2008). Principals' and counsellors' perceptions of physical aggression among secondary school students: A New Zealand view. New Zealand Journal of Educational Studies, 2.

Marsh, L., McGee, R., \& Williams, S. (2009). Teachers' perceptions of physical aggression among secondary school students: A New Zealand view. Australian journal of education, 53:3, 245-260.

Marshall, C., \& Rossman, G. B. (2010). Designing qualitative research. London: Sage.

Mncube, V. and Harber, C. (2012). The Dynamics of Violence in South African Schools: Report. University of South Africa.

Mishna, F., Scarcello, I., Pepler, D., \& Wiener, J. (2005). Teachers' understanding of bullying. Canadian Journal of Education/Revue canadienne de l'éducation, 718-738.

Mayer, M.J. (2008). Fact Sheet \#1: Overview of school violence prevention. Retrieved from http://www.ncsvprp.org/resources_assets/ CPSV\%20Fact\%20Sheet-1-Overview\%20of\%20School\%20Violence\%20Prevention-November-24-2008-Revision.pdf. Accessed on 14 February 2014.

Patton, M. Q. (2008). Utilization-focused evaluation. Newbury Park, CA: Sage.

Pinheiro, P. (2006). World Report on Violence Against Children, Geneva: United Nations.

PLAN. (2008). The Global Campaign To End Violence in Schools, Woking: PLAN.

Siann, G. Callaghan, M., Lockhart, R., and Rawson, L. (1993). Bullying: Teachers' views and school effects. Educational Studies, 19: 307-321. 
Silverman, D. (ed.). (2010). Qualitative research. New Bury Park: Sage.

Smith, A. \& Vaux, T. (2003). Education, Conflict and International Development, London: DfID.

South African Council of Educators. (2011). School-based violence report: An overview of school-based violence in Southern

Africa. Available at http;//www.sace.org.za/upload/files/School\%20Based\%20Violence\%20Report-2011.pdf. Accessed on 01 August 2014.

South African Institute of Race Relations (2008). South African schools most dangerous in the world. Available at http://www.saiir.org.za/ press. Accessed on 01 March 2010.

Strydom, H., \& Venter, L. (2002). Sampling and sampling methods. Research at grass roots for the social sciences and human service professions. Pretoria: Van Schaik.

The South African Human Rights Commission report on violence in schools (2008).

Ttofi, M. M., \& Farrington, D. P. (2011). Effectiveness of school-based programs to reduce bullying: A systematic and meta-analytic review. Journal of Experimental Criminology, 7:1, 27-56.

Townsend-Wiggins, C. (2001). Teachers' perceptions of and interventions in Episodes of bullying in schools. Dissertation Abstracts, 2001 2003/05.

Reza, A. Mercy J.A., \& Krug, E.G., (2001). The epidemology of violent deaths in the world, injury prevention, 7:2, 104-111.

World Health Organisation (WHO) (2002). World Report on Violence and Health. Geneva: WHO.

Zulu, B. M. \& Urbani, G. A. van der Merwe \& JL van der Walt. (2004). Violence as an impediment to a culture of teaching and learning in some South African schools. South African Journal of Education, 24:2, 170-5. 